Piotr Sawicki (1) Wyższa Szkoła Filologiczna, Wroctaw Uniwersytet Wrocławski (prof. em.) psawicki@uni.wroc.pl

\title{
De Cracovia (1985) a Cracovia (2016) Ojeada retrospectiva sobre los simposios hispánicos en Polonia
}

\begin{abstract}
Resumen:
El artículo narra la trayectoria de los estudios hispánicos en la Universidad Jaguelónica de Cracovia desde su nacimento en la mitad de los años 70 del siglo XX hasta hoy, presentando sus más importantes protagonistas, sus retos y sus alcances científicos, así como los más importantes simposios hispánicos en Polonia.
\end{abstract}

Palabras clave: romanistas de Cracovia, filología hispánica, Universidad Jaguelónica, simposios nacionales de hispanistas, Asociación Polaca de Hispanistas, revistas Aproximaciones, Estudios Hispánicos, Itinerarios, Studia Iberystyczne, Hispanica Posnaniensia, congresos intenacionales de hispanistas, Encuentros 2006-2016, Abre los ojos 2008-2013

\section{Abstract: \\ From Krakow (1986) to Krakow (2016). A Retrospective View at the Polish Congresses on Hispanic Studies}

The article recounts the history of Hispanic studies at the Jagiellonian University in Krakow from its foundation in the mid-70s of the 20th century up to now, presenting its leading figures, the challenges they have faced and their scientific achievements, as well as the most important Hispanic congresses in Poland. 
Keywords: Romance philologists of Krakow, Hispanic philology, Jagiellonian University in Krakow, National Hispanic Congresses, Polish Association of Hispanism, reviews Aproximaciones, Estudios Hispánicos, Itinerarios, Studia Iberystyczne, Hispanica Posnaniensia, International Hispanic Congresses Encuentros 2006-2016, Abre los ojos 2008-2013

Como estamos en Cracovia, invitados por su prestigiosa Universidad Jaguelónica, antes de pasar al tema central de mi ponencia, concebida como una especie de panorama retrospectivo de los simposios y congresos organizados por los hispanistas polacos, me parece oportuno presentar un sucinto informe sobre los inicios de nuestra disciplina en el centro académico de la antigua capital de Polonia ${ }^{1}$. Y esto no solo por cortesía hacia los organizadores de estos ENCUENTROS, sino por una razón primordial que no deberíamos olvidar.

Hace cuarenta años, en el curso académico 1975-1976, la hispanística cracoviana hizo su aparición en el mapa académico de Polonia como una nueva carrera de estudios filológicos. Nació en el seno del Instituto de Filología Románica, titulación entendida entonces en nuestro país como Filología Francesa. Hasta aquellas fechas, los jóvenes romanistas cracovianos tenían acceso a la lengua de Cervantes a través del lectorado de castellano, impartido como segunda lengua neolatina, del mismo modo que el italiano, el rumano, el portugués y, desde 1986, el catalán.

En cuanto al pluralismo lingüístico, conviene observar que la Filología Románica de Cracovia era una digna continuadora de una tradición que se remonta a los iniciadores de dicha disciplina en Polonia, con nombres tan ilustres como Edward Porębowicz (1862-1937), Zygmunt Czerny (1888-1975), Józef Dzierżykraj Morawski (18881939), Stanisław Wędkiewicz (1888-1963) y Władysław Folkierski (1890-1961). Wędkiewicz y Folkierski dirigían en los años treinta del

${ }^{1}$ El mismo tema fue objeto de mi artículo: „Asi se templó el acero. Los primeros años de la hispanística cracoviana, observados desde una prudente distancia”, Studia Iberystyczne, 2011, 10, pp. 37-50. Por esta razón, ciertas repeticiones son inevitables. 
siglo XX dos cátedras autónomas de romanística en la Universidad de Cracovia, mientras que en Leópolis (hoy Lviv, en Ucrania) había dos cátedras más, la de Porębowicz y la de Czerny, y en el período anterior a la II Guerra Mundial la lista se completaba con las correspondientes a otras cuatro ciudades universitarias: Varsovia, Poznań, Lublin y ViIna (hoy Vilnius, capital de Lituania) ${ }^{2}$.

Zygmunt Czerny, un romanista que demostró su interés por la cultura española prologando libros ${ }^{3}$ y colaborando en la traducción de obras clásicas (entre ellas, El Quijote) ${ }^{4}$, después de la guerra se estableció en Toruń, donde enseñó en la Universidad Nicolás Copérnico hasta el año 1952, cuando se hizo cargo de la Cátedra de Filología Románica de la Universidad Jaguelónica. Su traslado a Cracovia, en plena época estalinista, no fue casual. Las autoridades ministeriales redujeron entonces drásticamente el número de cátedras neofilológicas, por donde se infiltraba la cultura capitalista del "corrompido Occidente" (zgniły Zachód, en polaco), limitando su número, en el caso de la Filología Románica, a tan sólo dos, en Varsovia y en Cracovia. El germen de la futura hispanística cracoviana hay que buscarlo tanto en su propia determinación, como en la contribución de otra profesora procedente de Leópolis, Stefania Ciesielska-Borkowska (1889-1966), autora de la primera tesis postdoctoral (habilitacja) del área hispánica, dedicada a la recepción del misticismo español en nuestro país

${ }^{2}$ Para más detalles véase: J. Goldman (1937), "La philologie romane en Pologne", Archivum Neophilologicum, t. 2, pp. 202-207; A. Sawicka (2002), "El hispanismo polaco a finales del milenio", Iberoamericana, 5, pp. 195-212; P. Sawicki (2003), "Los vaivenes del hispanismo polaco (I): Inicios, desarrollo, expansión", Mundo Eslavo (Granada), 2, pp. 9-18.

${ }^{3}$ Z. Czerny (1970), "Posłowie", en: AA. Pieśń o Cydzie, trad. A.L. Czerny, Wydawnictwo Literackie, Kraków, pp. 119-135; idem (1975), "Posłowie", en: P. Calderón de la Barca, Dramaty, Wydawnictwo Literackie, Kraków, pp. 601-645.

${ }^{4}$ M. de Cervantes Saavedra (1972), Przemyślny szlachcic Don Kichote z Manczy, trad. A.L. y Z. Czerny, Państwowy Instytut Wydawniczy, Warszawa. 
(Ciesielska-Borkowska, 1939)5. Ciesielska-Borkowska se dedicó a la enseñanza del español y a la difusión de la literatura iberorrománica por medio de seminarios de licenciatura; entre sus alumnos figuraban los futuros hispanistas Teresa Eminowicz y Stefan Pieczara, vinculado posteriormente con la Universidad Adam Mickiewicz de Poznań. Tras su jubilación, destacó por su actividad en el ámbito del hispanismo la catedrática Maria Strzałkowa (1908-1975), romanista y, a la vez, investigadora de los nexos literarios hispano-polacos, autora del primer manual de historia de la literatura española publicado en Polonia después de $1945^{6}$. Strzałkowa continuó los esfuerzos de su predecesora, consiguiendo abrir en 1975 a los alumnos interesados por el mundo hispánico las puertas de la Filología Española, la segunda en Polonia, y creada tan solo tres años después de la inauguración de la así llamada iberística en la Univeridad de Varsovia (1972) ${ }^{7}$.

Detengámonos ahora en la fecha mencionada, que marca el comienzo oficial de los estudios hispánicos en Cracovia. Va precedida por la oportuna decisión de la directora del centro, profesora Strzałkowa, de contratar en 1974 a su antigua alumna, Teresa Eminowicz, autora de una memoria de licenciatura sobre la recepción de Lope de Vega en Polonia, como su mano derecha en la misión de preparar el programa de la nueva carrera. Lamentablemente, la promotora de este ambicioso proyecto no consiguió verlo realizado; murió el 7 de agosto de $1975^{8}$.

5 S. Ciesielska-Borkowska (1939), Mistycyzm hiszpański na gruncie polskim, Polska Akademia Umiejętności, Kraków.

${ }^{6}$ M. Strzałkowa (1966), Historia literatury hiszpańskiej, Ossolineum, Wrocław. Maria Strzałkowa es también autora de otro libro memorable: eadem (1960), Studia polsko-hiszpańskie, Nakładem Uniwersytetu Jagiellońskiego, Kraków.

7 Véase: P. Sawicki (2004), "Los vaivenes del hispanismo polaco (II): Docencia universitaria, investigaciones, publicaciones", Mundo Eslavo, 3, pp. 11-34 (en particular, pp. 11-12 y el apéndice bibliográfico pp. 24-34). Cf. también idem (2004), "Hispanismo polaco en el cambio de los milenios", Paralelo 50. Revista de la Consejería de Educación (Varsovia), 1, pp. 44-55.

${ }^{8}$ A la fallecida profesora la recordaron, en sendas publicaciones de carácter necrológico: A. Drzewicka (Kwartalnik Neofilologiczny, 1976, 4, pp. 517518 y Złota Księga Wydziału Filologicznego, 2000, Księgarnia Akademicka, 
Poco faltaba para que la Filología Hispánica naufragara antes de izar las velas, mas como la primera tanda de alumnos ya se había matriculado, su colaboradora recién contratada tomó la heroica decisión de no defraudar sus ilusiones. Hoy en día, cuando proliferan en Polonia hispanistas formados en Cracovia, doctores e incluso catedráticos, es difícil imaginarse el reto asumido por nuestra compañera, la Profesora Eminowicz, convertida de un día para otro en hispanista "todoterreno", responsable del programa y del buen funcionamiento de una nueva carrera universitaria.

Los años que mediaron entre la creación de la hispanística y la defensa del doctorado de Teresa Eminowicz ${ }^{9}$ representan el período más cosmopolita en la historia de dicha filología que pronto se abrió hacia el hispanismo internacional. Pasaron por Cracovia, durante temporadas lectivas de diferente duración, Andrés Michalski y Florian Śmieja, de Canadá; Luisa Roswell y Henryk Ziomek, de Estados Unidos; el traductor Jan Zych, de Méjico; Gabriela Makowiecka, de España. Esta última, precursora de los estudios eslavos en la Universidad Complutense y mediadora incansable entre las dos culturas, la polaca y la española ${ }^{10}$, vino a Cracovia con la misión de ofrecer a los hispanistas el primer seminario de licenciatura enfocado en temas literarios (de la tutoría de los seminarios de lingüística se encargó el profesor Stanisław Widłak, romanista e italianista). Pero, a mitad del curso académico 1978-1979, la hispanista madrileña se vio obligada a regresar a España por motivos familiares.

Kraków, pp. 648-652) y J. Heistein (Zagadnienia Rodzajów Literackich, 1976, 2, pp. 118-119).

${ }^{9}$ Doctorado titulado Hiszpania pierwszej polowy XVII wieku. Ideaty i rzeczywistość w prozie Złotego Wieku (directora de la tesis: prof. dra. Janina Z. Klave).

${ }^{10}$ Entre ellas: G. Makowiecka (1973), Luzán y su poética, Planeta, Barcelona; eadem (1981), La cultura eslava (coautor: Estanislao Makowiecki), Editora Nacional, Madrid; eadem (1984), Po drogach polsko-hiszpańskich, Wydawnictwo Literackie, Kraków-Wrocław. Sobre la investigadora escribieron, entre otros, G. Bąk, T. Eminowicz, B. Faron, C. Taracha y P. Sawicki. 
Fue en aquel momento cuando el destino hizo que se cruzaran, por un largo período, mis caminos profesionales con los de la hispanística cracoviana. Al recibir una amable invitación del director del Instituto de Filología Románica, Stanisław Widłak, decidí retomar la labor interrumpida por la profesora Makowiecka. Entre 1979 y 1982 pasaron por mis seminarios de licenciatura personas de gran talla intelectual como el traductor Piotr Fornelski muerto prematuramente (que luego preparó también bajo mi tutoría su tesis doctoral), Jerzy Styka (futuro catedrático y a la sazón ya doctor, de Filología Clásica), Anna Sawicka (directora del Departamento de Hispanística entre 2007 y 2015, a la vez traductora del castellano y del catalán), Magdalena Pabisiak (traductora de obras de teatro español clásico) o Bożena Wisłocka (investigadora especializada en la traducción). Paralelamente, se licenciaban los alumnos del profesor Widłak, lingüistas, como, por mencionar a los más destacados, Jerzy Sławomirski o Joanna Wilk-Racięska (hoy jefa del Departamento de Hispánicas en la Universidad de Silesia). Por las mismas fechas firmó sus primeras tutorías la Dra. Jadwiga Konieczna-Twardzikowa (1932-2009) ${ }^{11}$, traductora incansable y lingüista que colaboró con la hispanística desde el Instituto de Lengua Polaca de la Academia Polaca de Ciencias; fueron sus alumnas, aunque en un periodo algo posterior, la profesora Nina Pluta, de la Universidad Pedagógica de Cracovia y la Dra. Maria Filipowicz-Rudek, eminente galicista de la Universidad Jaguelónica. Entre las de la coordinadora de la Sección de Español, Dra. Eminowicz, figuran, para limitarnos a dos nombres que no necesitan presentación, Beata Baczyńska, catedrática de la Universidad de Breslavia, directora del Instituto de Filología Románica y Małgorzata Gaszyńska-Magiera, hoy colaboradora de la Universidad de Varsovia.

Al comienzo de la década de los ochenta el área de filologías minoritarias del Instituto de Filología Románica ya disponía de una buena plantilla de hispanistas, suficiente para cubrir la carga lectiva;

11 Sobre la prof. Twardzikowa véase el tomo 8 (2009) de Studia Iberystyczne que le dedicaron en homenaje sus compañeras y alumnos, en particular los textos de M. Filipowicz-Rudek ("Kalendarium życia. O nieustającym dialogu między Don Kichotem a Sancho Panzą") y P. Sawicki (“Trzydzieści lat, parę chwil - nie tylko w Krakowie. Glosa do portretu Jadwigi"). 
pudo contar también con la colaboración sistemática de dos romanistas, Stanisław Widłak y el polifacético catedrático Witold Mańczak (1924-2016), para dar conferencias y dirigir seminarios. Pero en aquel preciso momento la hispanística cracoviana, una prometedora carrera filológica que echaba raíces en un terreno poco cultivado, en unas circunstancias poco favorables para su desarrollo dada la falta de tradición académica de los estudios hispánicos en Polonia, recibió un duro golpe de la mano del Ministerio de Enseñanza Superior: en 1983 fue suspendida la admisión de alumnos, bajo el pretexto de no disponer de catedráticos con especialización hispánica. La nueva dirección del Departamento (con las catedráticas Urszula Dąmbska-Prokop y Anna Drzewicka a la cabeza) no se rindió sin luchar, ofreciendo a los candidatos, durante tres años, a falta de Filología Hispánica, un programa mixto, franco-español, dentro de la carrera de Filología Románica con una mención hispánica adicional.

Cuando obtuve, tras la publicación de una monografía sobre la narrativa de la Guerra Civil española ${ }^{12}$, el grado académico de doktor habilitowany (1984), la profesora Dąmbska-Prokop me propuso que reanudara la colaboración con la hispanística cracoviana. Acepté su oferta y a partir del mes de octubre del mismo año me puse a la disposición de la Universidad Jaguelónica que durante cinco años se convirtió otra vez en mi segundo puesto de trabajo, desde 1985 con jornada completa. De nuevo empecé a impartir seminarios, conferencias y cursos monográficos sobre la literatura española actual y, en ocasiones, sobre la historia de España. Dicho sea de paso, entre mis licenciados de aquella época figura nuestra anfitriona, la profesora Ewa Nawrocka, hoy directora del Departamento de Hispanística. La misión fue todo un éxito: el equipo docente cracoviano, fortalecido por un profesor (docent) de fuera, obtuvo por fin el visto bueno de las autoridades ministeriales que terminaron por permitir el acceso de nuevos alumnos en la Filología Hispánica (1986).

12 P. Sawicki (1985), Wojna domowa 1936-1939 w hiszpańskiej prozie literackiej. Ideologiczne konteksty literatury i jej misja społeczna, PWN, Warszawa. Cf. la versión española: idem (2010), La narrativa española de la Guerra Civil (1936-1975): Propaganda, testimonio y memoria colectiva, Biblioteca Virtual Miguel de Cervantes. 
Al comienzo del año 1985, cuando se acercaba el décimo aniversario de la inauguración de los estudios hispánicos en Cracovia, la profesora Dąmbska-Prokop reunió a sus colaboradores a fin de buscar la mejor manera de celebrarlo, y a la vez hacer llegar al dominio público la información sobre nuestras actividades y logros profesionales. Decidimos entonces organizar un simposio científico con el lema "Estudios polacos sobre la lengua y la cultura españolas" que, gracias al esfuerzo de su principal organizadora, Dra. Eminowicz, y sus excelentes contactos con los compañeros de otros centros, llegó a celebrarse entre el 15 y el 17 de diciembre de 1985 en el centro de la Academia de Ciencias Polaca en Mogilany, cerca de Cracovia.

Hay que destacar la importancia de esta efeméride, porque hasta entonces no había tenido lugar en Polonia ningún acto de tanta envergadura dentro del ámbito de nuestra disciplina. El Primer Simposio de Hispanistas Polacos (este fue su nombre oficial) dio la oportunidad de reunirse a los hispanistas (y lusitanistas: caso de la catedrática Janina Z. Klave, de la Cátedra de Iberística de Varsovia) de todo el país, desde Cracovia y Varsovia hasta Poznań, Gdańsk y Szczecin, y de presentar en total treinta ponencias. Entre sus autores figuraban, al lado de algún investigador veterano (como Henryk Ziomek, de University of Georgia), representantes de nuevas promociones, hoy nombres de primera fila en el campo del hispanismo polaco (Katarzyna Mroczkowska, Ewa Nawrocka, Wiaczesław Nowikow, Anna Sawicka, Elżbieta Skłodowska, Barbara Stawicka, Joanna Wilk-Racięska, Zygmunt Wojski); tampoco faltaron los romanistas con doble especialización (Anna Bochnakowa, Marek Gawełko, Witold Mańczak, Stanisław Widłak). La profesora Klave pronunció la conferencia inaugural ("Los problemas de la clasificación de la literatura española en los estudios polacos"), el eminente historiador Jan Kieniewicz (que tras la transición política en nuestro país ocuparía el cargo de primer embajador de la Polonia democrática en el Reino de España), clausuró el evento hablando de "España en la mitología nacional polaca" $"$.

${ }^{13}$ El Simposio fue objeto de un detallado informe de E. Skłodowska y Z. Wojski („I Ogólnopolskie Sympozjum Hispanistyczne. Mogilany 15-17 grudnia 
Cabe señalar también la fructífera presencia en este acto de un destacado lingüista de la Universitat de Barcelona, Dr. Ramon Cerdà Massó; no solamente por su intervención inaugural en la sección lingüística, sino también por inspirar una manera mejor en el estrechamiento de las relaciones entre ambas universidades, por medio de un intercambio de profesores contratados como lectores nativos. El intercambio empezó al año siguiente y brindó a varios hispanistas cracovianos la oportunidad de realizar largas estancias en Barcelona, en calidad de profesores asociados, y a los estudiantes de Cracovia, la ventaja de disfrutar del primer lectorado catalán en Polonia.

Un digno volumen, con 25 ponencias pronuciadas en aquel memorable simposio más un nada despreciable dossier bibliográfico, apareció tres años más tarde como Estudios Hispánicos $I^{14}$. El numeral ordinal incluido en la portada de las actas del simposio cracoviano posibilitó la inauguración de una serie editorial, continuada con el mismo título, Estudios Hispánicos ${ }^{15}$, en Breslavia, centro organizador del segundo (septiembre de 1990), luego también del tercero (abril de 1993) - y ya el último del ciclo iniciado en 1985 en Cracovia — Simposio de Hispanistas Polacos ${ }^{16}$.

1985 r.”, Kwartalnik Neofilologiczny, 1987, 1, pp. 118-119). Véase también L. Peters (1985), "Oby nie walczyli z wiatrakami. Na marginesie krakowskiego sympozjum hispanistycznego", Gazeta Krakowska, 15 XII.

${ }^{14}$ Véase T. Eminowicz, P. Sawicki, J. Sławomirski (eds.) (1988), Estudios Hispánicos I. Actas del Primer Simposio de Hispanistas Polacos. Kraków-Mogilany, 15-17 XII 1985, Nakładem Uniwersytetu Jagiellońskiego, Kraków.

${ }^{15}$ Véase P. Sawicki, J. Sławomirski (eds.) (1992), Estudios Hispánicos II. Actas del Segundo Simposio de Hispanistas Polacos, Wydawnictwo Uniwersytetu Wrocławskiego, Wrocław.

${ }^{16}$ Las actas del Tercer Simposio se editaron como los volúmenes 4 (1995) y 5 (1996) de Estudios Hispánicos, convertidos en 1994, por decisión de la Junta Directiva de la Universidad de Wrocław, en una publicación periódica, dirigida por Piotr Sawicki. Véanse: W. Nowikow (ed.) (1995), Lingüística española. Aspectos sincrónico y diacrónico, Wrocław y P. Sawicki, B. Baczyńska (eds.) (1996), Ideologías y poder. Aproximaciones a las literaturas hispánicas en los tiempos de crisis, Wrocław. 
La fórmula de simposios "nacionales" de carácter general, sin temario establecido previamente, resultó obsoleta en las nuevas circunstancias en las que empezó a moverse el hispanismo polaco, cada vez más vinculado, a través de las relaciones institucionales y contactos personales, con los centros académicos de Europa e Iberoamérica. Este cambio se refleja ya en los sucesivos números de Estudios Hispánicos. Mientras que en las actas del primero de los tres simposios aparecen solo los autores polacos (nuestro invitado catalán no nos remitió su ponencia), las del segundo evidencian la participación de unos profesores españoles y de lectores nativos, contratados por las universidades polacas (Waldo Cerezo Rubio, Pilar Gil Cánovas). En el tercer simposio la proporción de los hispanistas de fuera fue ya muy acusada; eran sobre todo representantes de centros relacionados con la Universidad de Wrocław, organizadora del evento, mediante convenios bilaterales (Valladolid, Universidad Autónoma de Barcelona, Lausana, Clermont-Ferrand) o compañeros con los que nos unía una colaboración a nivel individual. Nuestro hispanismo "simposional" se iba internacionalizando a grandes pasos.

Trataremos de ello a continuación pero antes quisiera señalar un hecho de suma importancia, sucedido en Varsovia el 7 y 8 de diciembre de 1985, que casi coincidió con nuestro Primer Simposio, celebrado una semana más tarde. Me refiero obviamente a la I Asamblea General de la recién creada Asociación Polaca de Hispanistas (Polskie Stowarzyszenie Hispanistów); su Junta Directiva (Zarząd Główny) fue presidida por Urszula Aszyk, y los dos vicepresidentes eran Teresa Eminowicz, por Cracovia y Piotr Sawicki, por Wrocław. Al mismo tiempo se constituyeron tres secciones regionales que agrupaban a los hispanistas de la Polonia central (Oddział Warszawski), meridional (Oddział Południowy) y occidental (Oddział Zachodni). La sección más activa fue, al parecer, la Occidental; junto con el Departamento de Iberística de la Universidad de Wrocław organizó, en los dos años siguientes, el coloquio "La España de la II República: política y literatura" (octubre de 1986) ${ }^{17}$ y el I Seminario de Metodología de

${ }^{17}$ Véase P. Sawicki (ed.) (1989), Hiszpania II Republiki: polityka i literatura, en Romanica Wratislaviensia, t. 32, Wydawnictwo Uniwersytetu Wrocławskiego, 
la Enseñanza de la Lengua Española (septiembre de 1987). El segundo, con la asistencia de más de 40 personas, entre ellos los lectores españoles de diversos centros académicos, pudo llevarse a cabo gracias a la cuantiosa subvención de la Embajada de España, representada en este evento por Carlos Marrodán Casas ${ }^{18}$.

La revista Estudios Hispánicos, nacida en Cracovia como actas de un simposio, no fue la primera iniciativa editorial de este tipo surgida en los años ochenta. Al congreso de Cracovia el profesor Kieniewicz aportó un proyecto muy avanzado: el de Aproximaciones, publicación concebida como órgano de expresión de los círculos académicos dedicados a la investigación de lo hispano (filólogos, historiadores, sociólogos, politólogos, etc.). La redacción iba a estar a cargo de Jan Kieniewicz, Ryszard Stemplowski y Urszula Aszyk, presidenta de la Asociación Polaca de Hispanistas, entidad patrocinadora de la revista. El contenido de los dos primeros números, de carácter monográfico, ya estaba programado. Desgraciadamente, por falta del esperado apoyo institucional, la iniciativa de Kieniewicz no llegó a cuajar y las personas invitadas a colaborar se quedaron con sus manuscritos en la mano. En consecuencia, los hispanistas de Varsovia tardaron diez años en estrenar su propia publicación periódica. El primer número de Itinerarios. Revista de estudios lingüísticos, literarios, históricos y antropológicos, aparecido en 1995, recogía artículos escritos por profesores y colaboradores de la Cátedra de Estudios Ibéricos, siendo un reflejo del carácter multidisciplinario de las investigaciones realizadas en dicho centro y de la docencia impartida. A pesar del anhelo de sacar un volumen cada año, el tomo segundo no salió hasta 1999; hoy Itinerarios tienen periodicidad semestral.

En el caso de mis compañeros de Cracovia, ante la sui generis “apropiación" del fruto del simposio de 1985 por los hispanistas de

Wrocław.

${ }^{18}$ Para fines administrativos utilizamos la denominación Ogólnopolska Konferencja Metodyczna „Dydaktyka języka hiszpańskiego w kształceniu uniwersyteckim, szkolnym i pozaszkolnym". Véase W. Nowikow, A. Murcia Soriano (1992), "Metodología de la enseñanza de la lengua española. Metodología y práctica", Romanica Wratislaviensia, 37, pp. ???. 
Breslavia, decidieron crear su propio medio de expresión. El título Studia Iberystyczne que encabezaba una sencilla colección de artículos de autores relacionados con este centro, editada en 1994 bajo la dirección de Urszula Dąmbska-Prokop y Teresa Eminowicz, reapareció cinco años más tarde (1999) al iniciar una nueva serie editorial con el mismo nombre. La revista fue destinada, en primer lugar, al público universitario desconocedor de la lengua castellana, de ahí que diese preferencia al idioma polaco y englobase, junto a los textos científicos, otros de divulgación ${ }^{19}$.

Para completar el panorama, conviene señalar la efímera existencia de una revista más, reducida a tres entregas, con tres distintos lugares de edición y un título que tuvo que ser modificado. Estas peculiares características corresponden a Hispanica Posnaniensia, un ambicioso proyecto del entonces director del Departamento de Hispanística de la Universidad de Poznań, profesor Rościsław Pazuchin. Su estreno, con el subtítulo aclaratorio Revista Internacional de la Universidad Adam Mickiewicz de Poznań dedicada al estudio de filologías y culturas del Mundo Hispánico, corresponde al año 1990. El editor la había concebido como plataforma de encuentro de los especialistas en filologías y culturas hispanas de la Europa Oriental que "aún siguen llevando a cabo sus actividades de investigación y de enseñanza con un cierto retraso y en un cierto aislamiento", con la llamada "Comunidad Mundial de Hispanólogos". Es difícil predecir cuál habría sido el carácter de Hispanica Posnaniensia si hubiera logrado sobrevivir. No obstante, tras un par de años, la hispanística, creada como sección autónoma de la Facultad de Filologías Modernas, fue incorporada al Instituto de Filología Románica y el profesor Pazuchin se marchó de Poznań. El

${ }^{19}$ A título de excepción, dado su carácter conmemorativo (XXXV aniversario de la fundación de Filología Hispánica en Cracovia), el „redondo” volumen décimo de Studia Iberystyczne (2011), salió en español. Véase la introducción al mismo, a cargo de Anna Sawicka, titulada „La Edad de Plata del hispanismo cracoviano (1975-2010). Textos y contextos" (pp. 7-19). El tomo contiene el índice del contenido de los números anteriores (varios de ellos en forma de ,almanaques" dedicados a las culturas minoritarias de España, la gallega y la catalana, así como al mundo lusitanófono); véase el „Apéndice”, pp. 317-330. 
número siguiente, con materiales de archivo procedentes del simposio organizado en 1989, fue publicado, bajo el título Hispanica Polonorum, diez años más tarde (1999) por la Escuela Superior de Pedagogía de Częstochowa y el último, en 2001 en Łódź, sin afiliación a ninguna institución académica ${ }^{20}$.

La idea de incorporar a los hispanistas de la Europa Central y Oriental a la "Comunidad Mundial de Hispanólogos", como la había llamado el profesor arriba citado, pronto tomó cuerpo gracias a la Fundación Duques de Soria. Esta prestigiosa institución organizó en junio de 1991 en Salamanca el coloquio internacional "El español y el futuro del hispanismo ante los cambios ocurridos en los países del Este de Europa”, con la participación de más de 30 hispanistas de Bulgaria, Checoslovaquia, Hungría, Polonia y Rumanía que tuvieron la posibilidad de presentar en un foro internacional el estado actual de estudios hispánicos en sus respectivos países y, a la vez, entablar contactos directos con renombrados catedráticos españoles invitados a este evento. El documento final del Coloquio, conocido luego como "Declaración de Salamanca", recogía una serie de postulados dirigidos "a la consideración general". Esta fórmula de cortesía fue ideada para apelar a las instituciones del Estado español (ministerios, universidades, el flamante Instituto Cervantes) pero, por falta del destinatario explicitado, todo quedó en el aire, siendo tan solo una expresión de nuestras inquietudes comunes, colectivamente articuladas.

Aunque el Coloquio de Salamanca tuvo cierto eco en la prensa española, sus efectos inmediatos se redujeron a la exposición pública, en España, de la situación precaria del hispanismo en el antiguo bloque del Este ${ }^{21}$. Sin embargo, el intercambio de información entre

${ }^{20}$ Para más detalles sobre las revistas científicas del hispanismo polaco del período anterior al siglo XXI véase P. Sawicki, A. Sawicka (2000), „Entre Aproximaciones e Itinerarios. Publicaciones periódicas de hispanistas polacos", en: II Coloquio Internacional. Tendencias y posibilidades de la hispanistica actual, Bratislava-Wien 2000, pp. 45-54.

${ }^{21}$ Es significativo el título, „Los hispanistas del Este piden ayuda al Gobierno y a las Universidades españolas", de la nota informativa que apareció en $A B C$ (22.06.1991, p. 54). 
los hispanistas centroeuropeos (p.ej. los de Polonia y Checoslovaquia, países vecinos pero separados por una frontera hasta entonces poco franqueable) y la constatación de que teníamos problemas parecidos por resolver, fue un estímulo para ir más lejos. En la sesión de clausura Jadwiga Konieczna-Twardzikowa y Piotr Sawicki presentaron el proyecto de crear en Cracovia, antigua capital del reino polaco-lituano y sede de la corte de los Jaguellones, un centro de información y coordinación del hispanismo del Este. Como punto de partida se planteó un congreso internacional de hispanistas, el primero en los países excomunistas ${ }^{22}$.

El provisional Comité Organizador del evento proyectado (Teresa Eminowicz de Cracovia, Piotr Sawicki de Wrocław y Leszek Biały, desde su puesto de secretario de la Embajada de Polonia), con la generosa ayuda del profesor Kieniewicz (en aquel entonces ya embajador en Madrid), hizo todo lo posible por conseguir el apoyo institucional y financiero, desde la propia Fundación Duques de Soria ${ }^{23}$ hasta el Instituto Cervantes, ya puesto en marcha. Lamento decirlo, pero todas nuestras gestiones fracasaron rotundamente y las puertas a las que fuimos ido llamando, tanto en Madrid como en España, permanecieron cerradas.

Me dediqué entonces a los preparativos del Tercer Simposio de Hispanistas Polacos (ya mencionado) pero sin abandonar la idea del

${ }^{22}$ Véase J. Konieczna-Twardzikowa, P. Sawicki, „Hispaniści z Europy Wschodniej, łączmy się - w Krakowie”, Dekada Literacka (Kraków), 1991, 23, p. 3.

${ }^{23}$ Conviene señalar que la Fundación, por su parte, organizó unos años más tarde la II Reunión de Hispanistas de los Países del Este de Europa (Salamanca, 23-24 de marzo de 2000). Los congresistas, procedentes de siete países (esta vez también de Rusia), tuvieron ocasión de encontrarse con representantes de entidades culturales españolas, del mundo empresarial y la Universidad española. Véase una detallada presentación de ambos coloquios salmantinos, así como del Congreso Internacional „España y el Mundo Eslavo. Relaciones lingüísticas, literarias y culturales" (Universidad Complutense, 11-13 de marzo de 2002) en: P. Sawicki (2002), „España y la Europa Centro-Oriental. Una ojeada retrospectiva sobre los simposios internacionales de hispanistas y eslavistas centroeuropeos (1991-2002)", Estudios Hispánicos, 10, pp. 221-229. 
congreso internacional, tanto más que ya se asomaba la fecha del vigésimo aniversario de la hispanística cracoviana. La Embajada de España nos ofreció la subvención solicitada y, finalmente, gracias a la perseverancia e inagotable energía de la Dra. Eminowicz y la colaboración del autor de esta ponencia, responsable de la programación del congreso, tras los cuatro años que mediaron entre la primera idea del encuentro de hispanistas europeos en la Ciudad del Vístula hasta su realización, llegó el momento tan esperado. El Primer Simposio Hispánico Internacional, bautizado con el nombre "La Europa del Centro y del Este y el Mundo Hispánico", tuvo lugar entre el 26 y el 28 de octubre de 1995, con la participación de unas sesenta personas procedentes de centros académicos de nueve países, desde Rusia y Ucrania hasta Rumanía y Bulgaria; por supuesto, no faltaron tampoco los españoles y latinoamericanos ${ }^{24}$.

Durante la cena de despedida el Dr. Miroslav Lenghardt, en nombre de la delegación eslovaca, declaró su disposición para organizar el siguiente simposio de hispanistas centroeuropeos en Bratislava, algo que todos recibimos con mucha ilusión. La promesa no pudo ser cumplida y los encuentros periódicos de quienes a orillas del Vístula, Vltava o Danubio nos dedicamos al cultivo de lo hispano se limitaron en los años siguientes a efémerides de menor alcance (como, por ejemplo, coloquios anuales de hispanistas de Eslovaquia y Austria, de un día de duración, organizados por la Universidad Comenio, de Bratislava y la Universidad de Viena entre 1998 y 2001, coordinados por el catedrático Ladislav Trup). No obstante, la propia Universidad Jaguelónica volvió a la idea que nos inspiró en 1995, conmemorando diez años más tarde el trigésimo aniversario de la creación de la carrera de español con un congreso internacional de un carácter parecido: "Retos del hispanismo en la Europa Central y del Este" (14-15 de octubre de 2005) ${ }^{25}$.

${ }^{24}$ Las Actas del congreso recogen 43 ponencias, precedidas por los textos introductorios de Teresa Eminowicz y Piotr Sawicki; véase A.I. Blanco Picado, T. Eminowicz (eds.) (1996), Europa del Centro y del Este y el Mundo Hispánico. Simposio Internacional de Hispanistas, Kraków.

${ }^{25}$ Véase L.F. Cercós García et al. (coords.) (2007), Retos del hispanismo en la Europa Central y Oriental. Actas del Congreso Internacional (...), Madrid. El 
También otros centros del hispanismo polaco siguieron la costumbre de celebrar sus aniversarios "redondos" con simposios conmemorativos de carácter internacional. La Cátedra de Estudios Ibéricos (desde 2001, Instituto de Estudios Ibéricos e Iberoamericanos) de la Universidad de Varsovia, celebró así su vigésimo aniversario (simposio "Diálogo Intercultural - Migración de Discursos. Domesticación de lo desconocido", octubre de $1991^{26}$ ), luego el vigésimoquinto (octubre de 1997) ${ }^{27}$. En diciembre de 1999, por iniciativa del catedrático Kazimierz Sabik, se conmemoró el primer lectorado académico de español, creado 80 años antes en Varsovia, con el simposio "Hispanismo europeo a fin de siglo", una excelente oportunidad para presentar el historial de estudios hispánicos en los seis centros polacos de esta disciplina en aquel momento (Varsovia, Cracovia, Breslavia, Poznań, Katowice, Lublin); es de lamentar que no hayan sido publicadas las actas de dicho simposio.

Por su parte, los hispanistas de la Universidad Adam Mickiewicz de Poznań organizaron, en mayo de 2001 y abril de 2002, sendos simposios titulados "Lengua, literatura: dimensión cultural", el primero, y "El enfoque social y cultural en los estudios lingüístcos y literarios", el segundo ${ }^{28}$. Los de la Universidad de Breslavia se conmemoraron en octubre de 2003, en un ambiente de intimidad, junto con sus antiguos

copioso volumen (961 págs.) recoge más de cien colaboraciones agrupadas en seis secciones, precedidas por cinco presentaciones diferentes (de parte de la Universidad Jaguelónica, la Embajada de España, el Instituto Cervantes, la Asociación Polaca de Hispanistas y la directora del Congreso, prof. Teresa Eminowicz) y tres conferencias inaugurales, dedicadas - como era de esperar en 2005- a Cervantes y El Quijote, a cargo de eminentes especialistas españoles.

${ }^{26}$ Sus actas fueron editadas en 1993 por el Centro Internacional de Estudios Latinoamericanos (CESLA) como número 9 de la serie Estudios y Memorias con el subtítulo: Memorias del Simposio Internacional de la Cátedra de Estudios Ibéricos. Warszawa-Konstancin, 15-19 de octubre de 1991.

${ }^{27}$ Véase "25. Aniversario de la Cátedra de Estudios ibéricos. Universidad de Varsovia. Memorias del Simposio Internacional. 8-10 de octubre de 1997", Itinerarios, 2000, 3/1 y 3/2, pp. ¿???.

${ }^{28}$ Véase B. Łuczak, J. Wachowska (2002), “Coloquios de Poznań 2001 y 2002”, Estudios Hispánicos, 10, pp. 235-236. 
profesores (entre ellos, los catedráticos Roberto Manberger Amorós y Wiaczesław Nowikow) y alumnos, el vigésimoquinto aniversario de la primera promoción de licenciados en Filología Románica con especialidad española ${ }^{29}$.

La lista de eventos parecidos, sobre todo de los encuentros dedicados a un determinado espacio temático o a un solo autor (desde Miguel de Cervantes hasta Sofía Casanova, escritora polonófila $i ?$ gallega), sería, al llegar a la segunda década del siglo XXI, casi inagotable. Mas, como el tiempo nos apremia, me limitaré a señalar dos iniciativas que casi coincidieron en el tiempo.

Como represento aquí a la Escuela Superior de Filología de Breslavia, me toca mencionar primero nuestro propio ciclo simposial, con el nombre Abre los ojos (por referencia a la famosa película española), inaugurado en mayo de 2008, en forma de unas simples jornadas didácticas. Los encuentros siguientes, ya de carácter internacional, tuvieron lugar en 2009 ("España adentro"), 2010 ("Del español al hispanismo: Docencia e investigación") $)^{30}, 2011$ ("Traducir una cultura a otra") 31 y 2013 ("Imagen de la mujer" - en la literatura, cultura y los medios de comunicación) ${ }^{32}$. En el último participó, impartienco la conferencia inaugural, Carme Riera, recién elegida miembro de la Real Academia Española.

Para finalizar mi intervención, quisiera ahora pasar a la iniciativa que nos ha reunido, el ciclo denominado ENCUENTROS que, estos días, en Cracovia, llega a la sexta edición. Todo empezó en la

${ }^{29}$ Véase M. Krupa (2003), "Conmemoración del 25 aniversario de los estudios de Románicas con especialidad en Hispánicas en la Universidad de Wrocław", Estudios Hispánicos, 11, pp. 310-312.

${ }^{30}$ Véase Z. Wąsik, M. Kolankowska (eds.) (2012), Del español al Hispanismo: Docencia e investigación, Wydawnictwo Wyższej Szkoły Filologicznej we Wrocławiu, Wrocław.

${ }^{31}$ Véase T. Jaromin, M. Kolankowska, P. Sawicki (eds.) (2014), Traducir una cultura a otra, Wydawnictwo Wyższej Szkoły Filologicznej we Wrocławiu, Wrocław.

${ }^{32}$ Las ponencias presentadas durante este simposio aparecerán en los tres primeros números de la revista Cuadernos Iberorrománicos, de reciente creación. 
Universidad de Silesia donde, por iniciativa de la profesora Joanna Wilk-Racięska, directora del Departamento de Hispánicas, fueron organizados los ENCUENTROS 2006. Entre el 30 de noviembre y el 2 de diciembre de este año, tras la conferencia inaugural a cargo de Jean-François Botrel, presidente de la Asociación Internacional de Hispanistas, se pronunciaron, en cinco aulas temáticas (Teatro, Literatura, Lingüística, Enseñanza del Español, Traducción e Interpretación) casi ochenta ponencias y comunicaciones ${ }^{33}$.

El ciclo iniciado en Katowice prosiguió en Lublin, en la Universidad Marie Curie-Skłodowska donde, bajo la dirección de la profesora Maria Falska, directora del Departamento de Español, transcurrieron en abril de 2008 los ENCUENTROS $2008^{34}$, para alojarse por tercera vez en la Universidad de Varsovia (octubre de 2010). Es de destacar el crecimiento númérico de congresistas, reflejado en la voluminosidad de los materiales postsimposiales publicados. Los ENCUENTROS 2010 dieron su fruto en forma de seis volúmenes de la colección con el mismo título, dirigida por la catedrática Urszula Aszyk y editada por el Instituto de Estudios Ibéricos e Iberoamericanos ${ }^{35}$. Después de los ENCUENTROS 2012 (Universidad de Wrocław, noviembre de

${ }^{33}$ Las actas, redactadas por J. Wilk-Racięska y J. Lyszczyna, salieron en tres volúmenes: Encuentros I (Encuentros de lingüistica, traducción y enseñanza de la lengua española, 2008), Encuentros II y Encuentros III (Encuentros con la literatura y el teatro del mundo hispano, 2008 y 2010), Oficyna Wydawnicza WW, Katowice.

${ }^{34}$ Las actas del simposio se publicaron en dos tomos: Encuentros literarios II. Estudios coordinados por M. Falska y Estudios lingüísticos II. Estudios coordinados por B. Brzozowska-Zburzyńska, UMCS, Lublin.

${ }^{35}$ Eran: La norma lingüistica del español (vol. 1, coord. E. Waluch de la Torre), Especificidad del texto dramático y la puesta en escena: dependencia o autonomía (vol. 2, coord. U. Aszyk), Traducción: ¿Manipulación o transformación necesaria? (vol. 3, coords. G. Beltrán, K. Dłużniewska-Łoś), ¿Dentro / fuera? Nuevas perspectivas sobre la identidad y la otredad en las literaturas hispánicas (vol. 4, coords. A. Flisak, K. Moszczyńska), De dioses y hombres. Creencias y rituales mezoamericanos y sus supervivencias (vol. 5, coords. K. MikulskaDąbrowska, J. Contel) y Estudios de historia, religión y arte en España y América Latina (vol. 6, coord. U. Lugowska). 
2012) salieron hasta siete volúmenes, esta vez no numerados, que constituyen un impresionante conjunto de monografías colectivas de temas hispánicos ${ }^{36}$. Dos años más tarde, la Universidad de Silesia fue de nuevo anfitriona de la magna empresa de la Asociación Polaca de Hispanistas. Los ENCUENTROS 2014 se celebraron en Ustroń (mayo de 2014); sus actas forman una colección de cinco tomos, titulada Relecturas y nuevos horizontes en los estudios hispánicos ${ }^{37}$.

Hoy los Simposios Internacionales de Hispanistas, organizados en Polonia en el ciclo bianual, vuelven a Cracovia, a la Universidad Jaguelónica, donde todo empezó en el memorable año 1985, año en el que nació nuestra asociación profesional, Polskie Stowarzyszenie Hispanistów, y se organizó un modesto Primer Simposio de Hispanistas Polacos.

${ }^{36}$ Los títulos de los sucesivos volúmenes son: Teorías narrativas e interdiscursivas en la prosa hispánica (eds. J.L. Losada Palenzuela, J. Ziarkowska), Entre artes, culturas y tiempos. Poesía y teatro hispánicos (eds. B. Baczyńska, M. Krupa), Historia y cultura de España y América Latina en las fuentes literarias, documentales y artísticas (eds. E.K. Kulak), Guerra, exilio, diáspora. Aproximaciones literarias e históricas (eds. A. August-Zarębska, T. Marín Villora), Traducción: contextos e implicaciones (eds. M. Gaszyńska-Magiera, J.C. Nowicka), Variación, contraste, circulación. Perspectivas lingüisticas en el hispanismo actual (eds. Z. Bułat-Silva, M. Głowicka, J. Wesoła) y Enseñanza y aprendizaje del idioma español. Retos, propuestas y perspectivas (ed. M. Świątek). La colección salió a la luz en 2014 (Wydawnictwo Uniwersytetu Wrocławskiego, Wrocław).

${ }^{37}$ Por el momento han aparecido: vol. 1: Literatura (poesía y narrativa) (eds. M. Kobiela-Kwaśniewska, J. Lyszczyna); vol. 2: Teatro (eds. K. Gutkowska-Ociepa, M. Kobiela-Kwaśniewska, J. Wilk-Racięska); vol. 3: Cultura y traducción (eds. S. Deditius, A. Nowakowska-Głuszak, J. Wilk-Racięska) y vol. 4: Lingüística y didáctica de la lengua española (eds. J. Wilk-Racięska, A. Szyndler, C. Tatoj), Katowice 2016, Wydawnictwo Uniwersytetu Śląskiego. 


\section{Bibliografía selectiva}

EMINOWICZ, T. (1988), "Los estudios hispánicos en Cracovia", Estudios Hispánicos I, pp. 13-15.

EMINOWICZ, T. (1996), "El vigésimo aniversario de estudios hispánicos en la Universidad Jaguellónica de Cracovia”, en: A. I. Blanco Picado, T. Eminowicz (eds.), Europa del Centro y del Este y el Mundo Hispánico. Simposio Internacional de Hispanistas. Cracovia, 26-28 de octubre de 1995, Kraków, pp. 7-8.

GOLDMAN, J. (1937), "La philologie romane en Pologne", Archivum Neophilologicum, t. 2, pp. 71-318.

KONIECZNA-TWARDZIKOWA, J., P. Sawicki (1991), „Hispaniści z Europy Wschodniej, łączmy się - w Krakowie”, Dekada Literacka (Kraków), 23, p. 3.

KRUPA, M. (2003), „Conmemoración del 25 aniversario de los estudios de Románicas con especialidad en Hispánicas en la Universidad de Wrocław", Estudios Hispánicos, 11, pp. 310-312.

ŁUCZAK, B., WACHOWSKA, J., (2002), „Coloquios de Poznań 2001 y 2002", Estudios Hispánicos, 10, pp. 235-236.

SAWICKA, A. (2002), "El hispanismo polaco a finales del milenio", Iberoamericana, 5, pp. 195-212, http://dx.doi.org/10.18441/ ibam.2.2002.5.195-112.

SAWICKA, A. (2011), "La Edad de Plata del hispanismo cracoviano (19752010). Textos y contextos", Studia Iberystyczne, 10, pp. 7-19, https:// www.doi.org/ 10.12797/SI.10.2011.10.01.

SAWICKI, P., SAWICKA, A. (2000), „Entre Aproximaciones e Itinerarios. Publicaciones periódicas de hispanistas polacos", en: II Coloquio Internacional. Tendencias y posibilidades de la hispanística actual, Bratislava-Wien, pp. 45-54.

SAWICKI, P. (1988a), "Kilka uwag na marginesie I Ogólnopolskiego Sympozjum Hispanistycznego", Estudios Hispánicos I, pp. 9-12.

SAWICKI, P. (1988b), "Primer Seminario de Didáctica del Español en Polonia", Cable. Revista del español como lengua extranjera, (Madrid), 2, p. 78. 
SAWICKI, P. (1996), “El Simposio Internacional «Europa del Centro y del Este y el Mundo Hispánico» y su circunstancia”, en: A. I. Blanco Picado, T. Eminowicz (eds.), Europa del Centro y del Este y el Mundo Hispánico. Simposio Internacional de Hispanistas. Cracovia, 26-28 de octubre de 1995, Kraków, pp. 9-10.

SAWICKI, P. (2002), „España y la Europa Centro-Oriental. Una ojeada retrospectiva sobre los simposios internacionales de hispanistas y eslavistas centroeuropeos (1991-2002)", Estudios Hispánicos, 10, pp. 221-229.

SAWICKI, P. (2003), "Los vaivenes del hispanismo polaco (I): Inicios, desarrollo, expansión”, Mundo Eslavo. Revista de Cultura y Estudios Eslavos, Universidad de Granada, 2, pp. 9-18.

SAWICKI, P. (2004a), "Los vaivenes del hispanismo polaco (II): Docencia universitaria, investigaciones, publicaciones", Mundo Eslavo. Revista de Cultura y Estudios Eslavos, Universidad de Granada, 3, pp. 11-34.

SAWICKI, P. (2004b), "Hispanismo polaco en el cambio de los milenios", Paralelo 50. Revista de la Consejería de la Educación (Varsovia), 1, pp. 44-55.

SAWICKI, P. (2011), „Así se templó el acero. Los primeros años de la hispánistica cracoviana, observados desde una prudente distancia”, Studia Iberystyczne, 10, pp. 37-50, http://dx.doi.org/10.12797/SI.10.2011.10.04. SKŁODOWSKA, E., WOJSKI, Z. (1987), „I Ogólnopolskie Sympozjum Hispanistyczne. Mogilany 15-17 grudnia 1985 r.”, Kwartalnik Neofilologiczny, 1, pp. 118-119. 